\title{
Ameliorative effect of metformin on methotrexate-induced genotoxicity: An in vitro study in human cultured lymphocytes
}

\author{
ABEER M. RABABA'H ${ }^{1}$, KAREM H. ALZOUBI ${ }^{1}$, OMAR F. KHABOUR ${ }^{2}$ and MERAABABNEH ${ }^{1}$ \\ ${ }^{1}$ Department of Clinical Pharmacy, College of Pharmacy; ${ }^{2}$ Department of Medical Laboratory Sciences, \\ Faculty of Applied Medical Sciences, Jordan University of Science and Technology, Irbid 22110, Jordan
}

Received February 16, 2021; Accepted April 22, 2021

DOI: $10.3892 /$ br.2021.1435

\begin{abstract}
Methotrexate is a folic acid antagonist that has been shown to be genotoxic to normal healthy cells. Metformin is an insulin-sensitizing agent, with multiple potential pharmacodynamic profiles. The aim of the present study was to evaluate the genotoxic effect of methotrexate on DNA and the potential ameliorative effect of metformin on chromosomal damage induced by methotrexate. The present study was performed in vitro, and the frequency of chromosomal aberrations (CAs) and sister chromatid exchanges (SCEs) in human cultured lymphocytes were measured. Blood samples from five non-smoking healthy men aged 20-35 years were donated and used in the present study. Treatment of cultured blood cells with methotrexate significantly increased the number of cells with CAs $(\mathrm{P}<0.0001)$ and the frequency of SCEs $(\mathrm{P}<0.0001)$. The chromosomal injury induced by methotrexate was significantly reduced by pretreatment of the samples with metformin $(\mathrm{P}<0.0001)$. Importantly, the treatment of the cells with metformin alone did not affect the frequency of SCEs compared with the control group $(\mathrm{P}>0.05)$. Additionally, methotrexate and metformin alone, and combined, induced significant decreases in the proliferative index compared with the control group $(\mathrm{P}<0.05)$. In conclusion, metformin ameliorated the genotoxicity induced by methotrexate in cultured human lymphocytes.
\end{abstract}

\section{Introduction}

Methotrexate (MTX), a folic acid antagonist, exhibits anti-proliferative activity, and immune- regulatory and anti-inflammatory properties (1-3). The chemical structure of MTX is: (2 )-2-[[4-[(2,4-diaminopteridin-6-yl) methyl methylamino] benzoyl]amino] pentanedioic acid (4). MTX

Correspondence to: Dr Abeer M. Rababa'h, Department of Clinical Pharmacy, College of Pharmacy, Jordan University of Science and Technology, PO Box 3030, Irbid 22110, Jordan E-mail: amrababah@just.edu.jo

Key words: methotrexate, metformin, chromosomal aberrations, proliferative index, sister chromatid exchanges, genotoxicity competitively inhibits the activity of dihydrofolate (DHF) reductase enzyme (DHFR), which is a small protein ( $19 \mathrm{kDa}$, 186 amino acids) that catalyzes the reduction of DHF into tertahydrofolate (THF) $(1,5)$. Moreover, THF is essential for the synthesis of purines and several amino acids, as well as for DNA synthesis (5).

The clinical use of MTX as an antimetabolite in cancer management is associated with dose-dependent toxic adverse effects, such as alopecia, ulcerations, pulmonary toxicity, abdominal discomfort, hepatotoxicity, myelosuppression and nephrotoxicity $(6,7)$. Moreover, the administration of MTX is associated with neurotoxicity that is reported along with neurological complications, delays in treatment and prolonged hospitalization $(8,9)$. MTX administration also causes genetic alterations and DNA damage by enhancing the accumulation of oxidative DNA lesions $(10,11)$. Furthermore, MTX has been reported to cause double-stranded breaks, which can result in chromosomal relocations, and is extremely harmful to dividing cells $(12,13)$. Previous studies have revealed the significant role of oxidative stress as a participating factor in neurotoxicity and hepatotoxicity (14-16). Hence, the excessive production of reactive oxygen species (ROS) contributes to the incidence and advancement of MTX-induced toxicity (17). The redox-state altering properties of MTX have been suggested as an essential immunosuppressive mechanism and found to induce apoptosis via ROS production (1). The produced reactive species react with different biological macromolecules, thereby generating lipid peroxides that are capable of producing additional ROS or converting them into reactive compounds that are able to crosslinks within DNA and proteins, resulting in cellular toxicity $(14,18)$. Thus, it is hypothesized that cellular oxidative damage with lipid peroxidation is a characteristic of MTX-induced toxicity. Moreover, a decrease in tetrahydrobiopterin levels (an important cofactor for nitric oxide synthesis that is produced by the DHFR) potentiates MTX-induced ROS production (1). Antioxidants function to reverse the increase in oxidative stress induced by MTX. Currently, to the best of our knowledge, there are no studies aiming to antagonize the genotoxicity induced by MTX. Thus, identifying an agent that can ameliorate the MTX-induced genotoxicity may significantly improve the outcomes of patients who are administered MTX.

Metformin, a biguanide anti-hyperglycemic drug, is the first-line agent used in the management of type 2 diabetes mellitus. It reduces hepatic glucose synthesis, decreases glucose 
intestinal absorption and increases insulin sensitivity by elevating peripheral glucose uptake and consumption $(19,20)$. Additionally, metformin is widely used in the treatment of polycystic ovary syndrome and as an adjunct treatment for cancer (19-22). The molecular mechanisms responsible for the effects of metformin may include, but are not limited to: The reduction of cellular oxidative stress, the suppression of inflammation and the reduction of levels of inflammatory biomarkers through 5' AMP-activated protein kinase-dependent and independent pathways (23). Cheki et al (24) reported that metformin has potential protective effects against cisplatin-induced genotoxicity in rat bone marrow cells due to its antioxidant properties. Moreover, another study demonstrated that metformin exerted protective effects against acetaminophen-induced liver toxicity by reducing overall hepatic oxidative stress (25). Thus, the present study aimed to assess the potential ameliorative effects of metformin against MTX-induced genotoxicity in cultured human lymphocytes.

\section{Materials and methods}

Participants. In the present study, peripheral venous blood was collected from five male subjects (median age 30 years old). The participants did not consume alcohol or drugs, did not smoke cigarettes/or waterpipe tobacco and were not on any medications. The blood samples were freshly collected from donors (pre-dietary intake) on the same day of the experiments to diminish any possible dietary effects. Written informed consent was obtained from all participants who decided to participate in the present study after providing them with an explanation of the aims and the objectives of the present study, and the present study was approved by the Institutional Review Board of Jordan University of Science and Technology (approval no. 27/132/2020). Additionally, the present study was performed in accordance with guidelines described in the Declaration of Helsinki (26) for research involving humans.

Human blood cell culture and drug treatment. The blood samples were cultured within $1 \mathrm{~h}$ of collection. Each sample of freshly drained blood $(1 \mathrm{ml})$ was mixed with $9 \mathrm{ml}$ culture medium (PB-MAX ${ }^{\mathrm{TM}}$ Karyotyping Medium; Gibco; Thermo Fisher Scientific, Inc.). PB-Max (Gibco; Thermo Fisher Scientific, Inc.) is an optimized fully supplemented RPMI-1640 medium that includes 15\% FBS, L-glutamine and phytohaemagglutinin (a mitogen that stimulates the division of blood lymphocytes) (10,27-29).

A stock solution of $2.2 \mathrm{mM}$ MTX ( $\geq 98 \%$ purity, Sigma-Aldrich; Merck KGaA) was prepared using sodium hydroxide as a solvent. The final concentration of MTX in the culture medium was $0.5 \mu \mathrm{M}$, and it was added to the cell culture $24 \mathrm{~h}$ before harvesting. Human cultured lymphocytes require $\sim 24 \mathrm{~h}$ to complete one cycle of cell division (30). Therefore, the $24 \mathrm{~h}$ exposure window was selected to make sure that cultured cells were exposed to drugs in all phases of the cell cycle. The MTX concentration used was based on previously published literature which showed that MTX-induced chromosomal damage $(5,10)$. Metformin (kindly provided by MS Pharma-United Pharmaceutical Manufacturing Company ${ }^{\circledR}$ ) was added to the corresponding flasks. The final metformin concentration in the culture medium was $12 \mu \mathrm{M}$ and it was added at the beginning of culture. The metformin concentration used in the present study was based on previously published literature (31). To assess the effects of MTX and/or metformin on DNA, four different groups were used: Control, metformin, MTX and metformin + MTX groups. A total of $2 \mathrm{~h}$ prior to harvesting, $100 \mu 110 \mu \mathrm{g} / \mathrm{ml}$ Colcemid (a spindle inhibitor; cat. no. 477-30-5; Sigma-Aldrich; Merck KGaA) was added to arrest mitosis at the metaphase stage. The procedure of human lymphocyte cell culture preparation was performed according to previously published protocols $(10,29,32)$.

Chromosomal aberration (CA) assay. The cultured cells were transferred into screw capped $15-\mathrm{ml}$ tubes and centrifuged at $134 \mathrm{x} \mathrm{g}, 4^{\circ} \mathrm{C}$ for $10 \mathrm{~min}$. The supernatant was then removed and the pellet was resuspended using pre-warmed KCL solution $(0.56 \% \mathrm{KCL})$ followed by incubation at $37^{\circ} \mathrm{C}$ for $30 \mathrm{~min}$. Subsequently, the lymphocytes were centrifuged for $10 \mathrm{~min}$ at $134 \mathrm{x} \mathrm{g}, 4^{\circ} \mathrm{C}$ to collect swollen lymphocytes. The supernatant was then removed and the pellets were fixed by the addition of the freshly prepared fixative, absolute methanol and glacial acetic acid [3:1 (v/v)] in a drop-wise manner, followed by incubation in the dark for $20 \mathrm{~min}$ at room temperature. The pellet was then washed three times using the aforementioned fixative solution and suspended in $\sim 1 \mathrm{ml}$ fixative solution. Then, the suspended solution was dropped on pre-chilled slides to disperse the metaphases. Finally, the slides were allowed to dry and were then dyed with 5\% Giemsa (Sigma-Aldrich; Merck $\mathrm{KGaA}$ ) for 4 min at room temperature, rinsed with distilled water and then air-dried for the CA test. CAs were evaluated in 100 well-spread metaphases for each group/donor (two repeats per donor were used) using a high-resolution light microscope (Nikon Corporation) with immersion oil at $\mathrm{x} 1,000$ magnification. The CAs were classed as gaps or breaks/exchanges.

Sister chromatid exchange (SCE) assay. The blood cultures were treated with $25 \mu 1$ 5-bromo-2-deoxyuridine (BrdU $0.01 \mathrm{~g} / \mathrm{ml}$; cat. no. 72218-68-9; Gibco; Thermo Fisher Scientific, Inc.) prior to the incubation period. As BrdU is highly susceptible to light, the procedures were performed in the dark to prevent photolysis. The protocols of cell culture preparation, cell harvesting/dropping and slide preparation were comparable to those used in the CA assay. The prepared slides for SCE were stained at room temperature for $22 \mathrm{~min}$ with $10 \mu \mathrm{g} / \mathrm{ml}$ Hoechst 32285 dye, then rinsed with distilled water and mounted in Mcllvaine buffer $(0.18 \mathrm{~g}$ citric acid and $2 \mathrm{~g}$ sodium phosphate dissolved in $100 \mathrm{ml}$ distilled water; $\mathrm{pH}$ 8.0). Subsequently, the prepared slides were exposed to two UV lamps $(350 \mathrm{~nm})$ at a distance of $7 \mathrm{~cm}$ at $40^{\circ} \mathrm{C}$ for $30 \mathrm{~min}$. Subsequently, the slides were washed carefully with distilled water and dried at room temperature. The slides were then stained at room temperature for 4 min using 5\% Giemsa stain in Gurr buffer (pH 6.8; Gibco; Thermo Fisher Scientific, Inc.), washed with distilled water and air-dried at room temperature. For SCE scoring, 50 well-spread second-division metaphases (M2) per donor that contained 42-46 chromosomes were scored using a high-resolution light microscope (Nikon Corporation) with immersion oil at x1,000 magnification as described above. M2 chromosomes were distinguished based on the presence of two differentially stained chromatids (one 
Table I. Frequency of chromosomal aberrations per donor induced by the different treatments ${ }^{\mathrm{a}}$.

\begin{tabular}{|c|c|c|c|}
\hline Donor/treatment & $\begin{array}{l}\text { Frequency of chromatid/ } \\
\text { chromosome exchanges }\end{array}$ & $\begin{array}{c}\text { Frequency of chromatid/ } \\
\text { chromosome breaks }\end{array}$ & $\begin{array}{c}\text { Frequency of chromatid } \\
\text { /chromosome gaps }\end{array}$ \\
\hline \multicolumn{4}{|l|}{ Donor 1} \\
\hline Control & 0 & 0.03 & 0.12 \\
\hline Metformin & 0.01 & 0.03 & 0.06 \\
\hline Methotrexate & 0.06 & 0.16 & 0.25 \\
\hline Methotrexate + Metformin & 0.05 & 0.06 & 0.09 \\
\hline \multicolumn{4}{|l|}{ Donor 2} \\
\hline Control & 0.01 & 0.04 & 0.1 \\
\hline Metformin & 0 & 0.02 & 0.05 \\
\hline Methotrexate & 0.08 & 0.17 & 0.28 \\
\hline Methotrexate + Metformin & 0.04 & 0.07 & 0.08 \\
\hline \multicolumn{4}{|l|}{ Donor 3} \\
\hline Control & 0 & 0.05 & 0.13 \\
\hline Metformin & 0.01 & 0.02 & 0.08 \\
\hline Methotrexate & 0.07 & 0.16 & 0.25 \\
\hline Methotrexate + Metformin & 0.05 & 0.09 & 0.07 \\
\hline \multicolumn{4}{|l|}{ Donor 4} \\
\hline Control & 0 & 0.03 & 0.1 \\
\hline Metformin & 0 & 0.04 & 0.06 \\
\hline Methotrexate & 0.07 & 0.19 & 0.26 \\
\hline Methotrexate + Metformin & 0.04 & 0.06 & 0.09 \\
\hline \multicolumn{4}{|l|}{ Donor 5} \\
\hline Control & 0.01 & 0.04 & 0.12 \\
\hline Metformin & 0.01 & 0.04 & 0.05 \\
\hline Methotrexate & 0.06 & 0.22 & 0.27 \\
\hline Methotrexate + Metformin & 0.04 & 0.08 & 0.1 \\
\hline \multicolumn{4}{|l|}{ Total mean } \\
\hline Control & 0.004 & 0.038 & 0.114 \\
\hline Metformin & $0.006^{\mathrm{c}, \mathrm{d}}$ & $0.030^{\mathrm{c}, \mathrm{d}}$ & $0.060^{\mathrm{b}-\mathrm{d}}$ \\
\hline Methotrexate & $0.068^{\mathrm{b}, \mathrm{d}}$ & $0.180^{\mathrm{b}, \mathrm{d}}$ & $0.262^{\mathrm{b}}$ \\
\hline Methotrexate + Metformin & $0.044^{\mathrm{a}, \mathrm{b}}$ & $0.072^{\mathrm{a}}$ & $0.086^{\mathrm{a}, \mathrm{b}}$ \\
\hline P-value & $\mathrm{P}<0.0001$ & $\mathrm{P}<0.0001$ & $\mathrm{P}<0.0001$ \\
\hline
\end{tabular}

${ }^{a}$ Frequency was calculated based on scoring of 100 cells per each treatment/donor. ${ }^{b}$ Significantly different from the control group. ${ }^{\mathrm{c}}$ Significantly different from the methotrexate group. ${ }^{\mathrm{d}}$ Significantly different from the methotrexate + metformin group.

lightly and the other darkly stained). Conversely, chromosomes in the M1 phase were distinguished by having both chromatids darkly stained. Chromosomes in the M3 phase were differentiated by exhibiting a combination of differentially stained chromatids, whereas chromosomes in the M4 phase had both chromatids lightly stained (10). To perform the cell kinetics analysis, the proliferative index (PI) was calculated via scoring 100 metaphases from each donor using the following formula: $(1 \times \mathrm{M} 1+2 \times \mathrm{M} 2+3 \mathrm{x} \geq \mathrm{M} 3) / 100$; where M1, M2 and M3 represent the number of cells at the first, second and third metaphases, respectively (29).

Statistical analysis. Data analysis was performed using GraphPad Prism version 7 (GraphPad Software, Inc.). Multiple comparisons were performed using a one-way ANOVA followed by a Tukey's post hoc test. Data are presented as the mean \pm standard error of the mean. $\mathrm{P}<0.05$ was considered to indicate a statistically significant difference.

\section{Results}

The effect of metformin $(12 \mu \mathrm{M})$ on MTX $(0.5 \mu \mathrm{M})$-induced genotoxicity in cultured human lymphocytes was examined using CA assays. The frequency of CAs induced by the indicated drugs is presented in Table I. Treatment of the cultured cells with MTX significantly increased the number of CAs. This included aberration exchanges $(\mathrm{P}<0.0001)$, chromatid/chromosome breaks $(\mathrm{P}<0.0001)$ and gap aberrations $(\mathrm{P}<0.0001)$. With respect to metformin, no significant changes in the frequency of all examined CAs were observed $(\mathrm{P}>0.05)$. However, 
co-treatment of the cultures with MTX and metformin induced significantly fewer CAs compared with the group treated with MTX alone $(\mathrm{P}<0.0001)$. The reduction in the frequency of CAs ranged between $35 \%$ of aberrations exchanges to $67 \%$ in gap aberrations. The trend in changes in the frequency of CAs induced by MTX and metformin was observed in cells obtained from different blood donors (Table I).

The SCE frequencies were increased in the MTX-treated human lymphocytes compared with other treatment groups $(\mathrm{P}<0.0001$; Fig. 1). When the cells were treated with metformin, lymphocytes were protected against the genotoxic effects of MTX $(\mathrm{P}<0.0001)$. The results of the present study revealed that MTX $(0.5 \mu \mathrm{M})$ led to a statistically significant increase in the frequency of SCEs in normal healthy lymphocytes $(\mathrm{P}<0.0001)$. However, pre-treatment of the cells with metformin $(12 \mu \mathrm{M})$ induced a significant decrease in the SCE frequency; it should be noted that the SCE frequency did not return to normal levels. Furthermore, treatment of the cells with metformin alone did not affect the frequency of SCE compared when compared with the control group $(\mathrm{P}=0.4278)$.

The effects of MTX and metformin on the PI are shown in Fig. 2. MTX and metformin, when used alone and when used in combination, induced a significant decrease in the PI compared with the control group $(\mathrm{P}<0.0001 ;$ Fig. 2). In addition, a significant difference in the PI was observed between the group treated with metformin alone and the MTX + metformin-treated group $(\mathrm{P}<0.0001)$. Fig. 3 provides representative images and examples of the chromosomal damage (ring and gap aberrations, SCEs and chromosomal exchange) observed in the present study.

\section{Discussion}

Previous studies have shown that treatment with several of the most effective anticancer agents causes direct cellular toxicity $(1,16,28)$. Furthermore, treatment with various anticancer agents has been demonstrated to exert carcinogenic, teratogenic and mutagenic effects in experimental environments. For example, MTX administration has been shown to enhance the accumulation of oxidative DNA injuries, which, in turn, have been shown to induce DNA damage $(11,33)$. Hence, protecting normal cells from conditions that may cause malignancy is an essential means to inhibit long-term impairments or damage due to the administration of chemotherapeutic agents.

Metformin remains the first-line medication used for the treatment of patients with type 2 diabetes mellitus. Several studies have demonstrated that metformin exhibits antioxidant, anti-apoptotic and anti-inflammatory properties (34-37). The aim of the present study was to investigate the potential ameliorative effects of metformin on the genotoxicity induced by MTX in human cultured lymphocytes. The cytogenetic effects were examined by performing CA and SCE assays in vitro. Both CAs and SCEs are commonly utilized as determining factors of DNA damage and genotoxicity, and both assays are widely used for examining the genotoxicity of therapeutic drugs and environmental agents (38-41).

The primary results of the present study indicated the ability of metformin to decrease the genotoxicity induced by MTX, as shown by the reduction in the frequencies of CAs and SCEs in the cells pre-treated with metformin. The results obtained

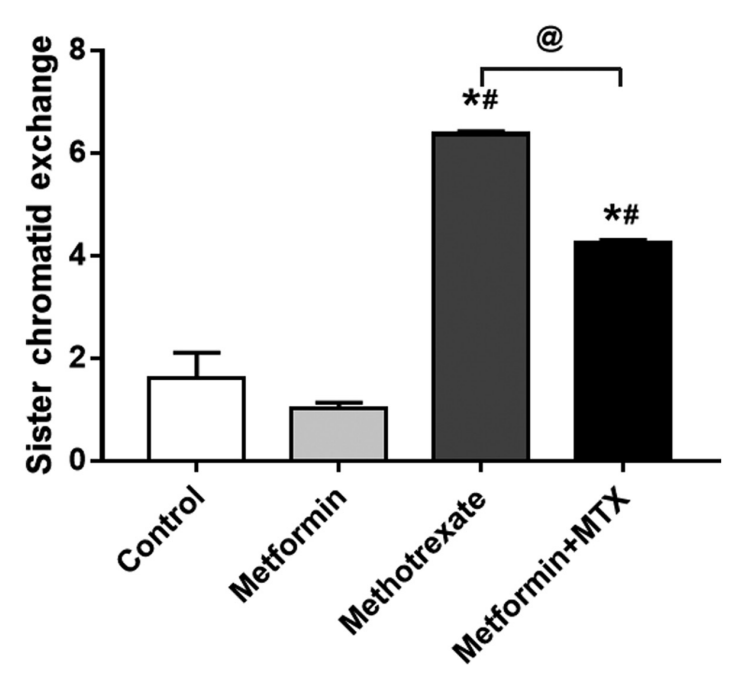

Figure 1. Average frequency of SCEs in the control, metformin, methotrexate, and the metformin + MTX groups. There was an increase in the SCE frequencies in MTX-treated human lymphocytes compared with the other treatment groups $(\mathrm{P}<0.0001)$, whereas treatment with metformin alone did not affect the frequency of SCE compared with the control $(\mathrm{P}=0.4278)$. Data are presented as the mean \pm the standard error of the mean. ${ }^{*} \mathrm{P}<0.05$ vs. control group; ${ }^{\text {}} \mathrm{P}<0.05$ vs. metformin group; ${ }^{\circledR} \mathrm{P}<0.05$ vs. metformin + methotrexate combination group. SCE, sister chromatid exchange; MTX, methotrexate.

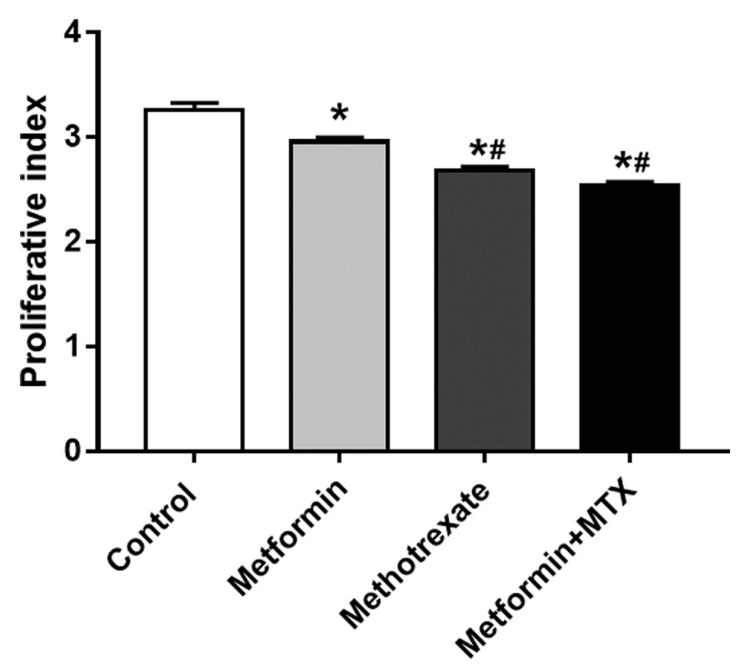

Figure 2. PI of the human cultured blood cells treated with metformin, MTX, and metformin + MTX combination. The figure shows a significant decrease in the PI of MTX and metformin, either alone or in combination, when compared with the control group $(\mathrm{P}<0.0001)$. The PI was calculated as follows: $(1 \times \mathrm{M} 1+2 \times \mathrm{M} 2+3 \mathrm{x} \geq \mathrm{M} 3) / 100$; where $\mathrm{M} 1, \mathrm{M} 2$ and $\mathrm{M} 3$ represent the number of cells at the first, second and third metaphases, respectively. ${ }^{*} \mathrm{P}<0.05$ vs. control group; ${ }^{\#} \mathrm{P}<0.05$ vs. metformin group. Data are presented as the mean \pm the standard error of the mean. PI, proliferative index.

in the present study revealed that the SCE and CA frequencies in the MTX treated cells were significantly higher compared with those in the control group, showing the genotoxic effects of MTX on normal healthy cells. These findings are in agreement with those of a previous study, where the genotoxicity of MTX was also shown (10). Moreover, it has been shown that MTX substantially increases the frequency of CAs in cultured human lymphocytes (42). Similarly, Atteritano et al (43) demonstrated a marked increase in the SCE frequency in the MTX group in patients with rheumatoid arthritis. Another 
A

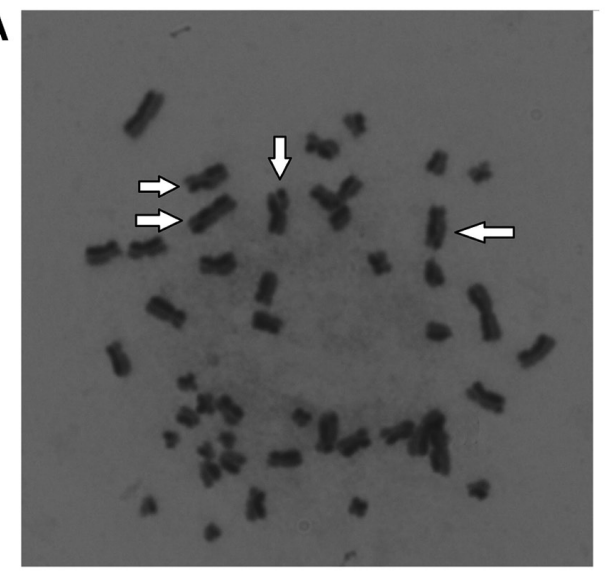

C

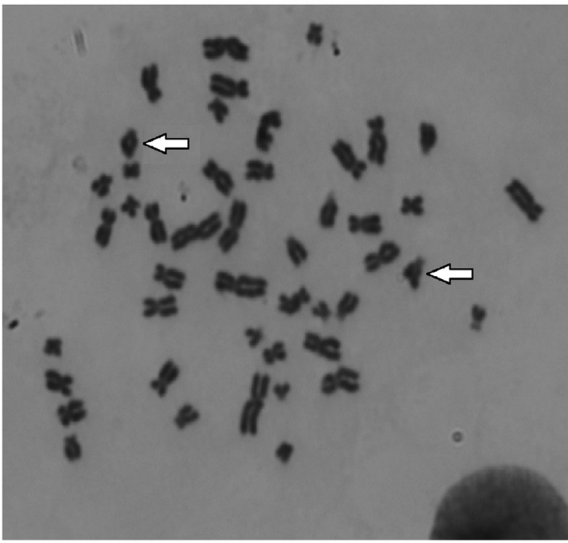

B

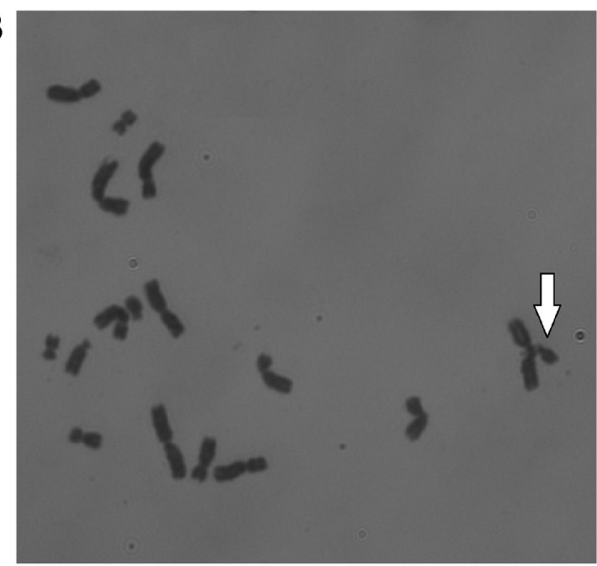

D

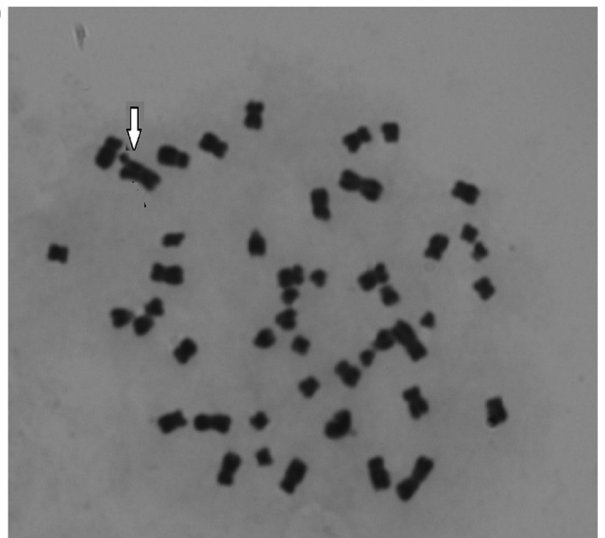

Figure 3. Representative images of chromosomal damage. (A) Several SCEs indicated by different arrows. (B) A chromosomal exchange involving 3 chromosomes. (C) A ring aberration (left arrow) and a terminal deletion (right arrow), and (D) a gap aberration. SCE, sister chromatid exchange.

study by Said Salem et al (44) reported a significant increase in the number of micronucleated polychromatic erythrocytes in mouse bone marrow cells treated with MTX compared with the corresponding controls.

A suggested mechanism underlying the increase in CA and SCE frequencies in cultured lymphocytes treated with MTX may involve the generation of ROS induced by MTX, which potentiate cellular damage (25). Several anticancer agents, including MTX, induce cellular genotoxicity via DNA oxidation, ROS production and reducing the total antioxidant capacity $(17,44)$. Several studies have demonstrated that metformin exerts antioxidant activities by reducing the malondialdehyde serum concentrations and increasing the activities of superoxide dismutase, catalase and glutathione reductase (45-47). The results of the present study revealed that the administration of metformin decreased the chromosomal damage induced by MTX, as evidenced by a prominent decrease in the CA and SCE frequencies. Collectively, it was suggested that metformin can attenuate the genotoxic effects on normal cells induced by MTX by attenuating oxidative stress through reducing ROS generation. This finding is in agreement with the results reported in an animal study by Ashoka and Mustak (48), which revealed the protective effect of rutin, a potent antioxidant flavonoid composite, in preventing MTX-induced genotoxicity. However, further human in vivo studies are required to confirm these results.

The results of the present study demonstrated that metformin reduced the incidence of spontaneous SCE, break and gap frequencies compared with the control. Hence, metformin appears to decrease the spontaneous levels of SCEs and gap aberrations, possibly via the reduction of the basal oxidative stress level. However, the detailed mechanisms responsible for this suppressive effect requires further investigation.

The protective effects of metformin on DNA damaging agents was documented in several studies. For example, using HepG2 cells, metformin has been shown to protect against DNA damage induced by formaldehyde (49). In a study that was performed using cells derived from elderly subjects, metformin has been shown to protect against pro-oxidant stimulus-induced DNA damage (50). Finally, using human A549 cells, metformin conferred protection against UVC-induced DNA damage (51). Thus, using different models, metformin seems to be a potent option for use with agents that induce cellular DNA damage.

In the present study, to assess the cytotoxicity of MTX and metformin, cell kinetic analysis was performed, which involves the determination of the PI. Following treatment of the cultured cells with MTX for $24 \mathrm{~h}$, it was found that MTX was cytotoxic to healthy normal human lymphocytes, as evidenced by the significant reduction in the calculated PI. However, metformin was not capable of attenuating the cytotoxic effects of MTX, and a slight further decrease in the PI was observed with the use of metformin. The results of the present study are consistent with those of previous research, where it has been demonstrated that MTX reduced the PI of cultured human lymphocytes (10) and other cell types, such as neurons and 
cancer cells. However, in a study that was conducted on rats, treatment of animals with metformin ameliorated the reduction in the number of proliferating cells, and the survival of the cells and immature neurons induced by MTX in the brain (52). Thus, the combined effects of metformin and MTX could differ according to model and or tissues used. The mechanisms by which MTX induced reduction in cellular proliferation include the induction of the intracellular ROS, interference with pyrimidine metabolism, activation of cellular apoptosis, reduction of methyltransferase activity and the reduction in cellular utilization of folates $(53,54)$. Therefore, the observed weak impact of metformin on MTX-induced inhibition of cellular proliferation could be due to the multiple mechanisms utilized by this drug to mediate its effects. Collectively, both metformin and MTX appeared to modulate changes in the PI in cultured human lymphocytes; pre-treatment of the cells with metformin did not lead to any marked alterations in the MTX-mediated reduction in PI. The PI was evaluated to examine the influence of metformin on the cytotoxicity of MTX, and was not predicted to imitate the genotoxicity findings.

The present study has some limitations, including the subjectivity in the genotoxicity parameter scoring (CAs, SCEs and PI), and the lack of in vivo experiments. Hence, further in vitro and in vivo studies are required to confirm the findings presented herein, and to extrapolate a small in vitro study to a large comprehensive analysis using larger sample sizes. Moreover, MTX genotoxicity was detected at $24 \mathrm{~h}$ following treatment with a single dose. Thus, further studies investigating the dose-response effects with longer treatment durations are required. This could provide a basis for future experimental study to improve our understanding of the molecular mechanism underlying the actions of MTX. Finally, in the present study, oxidative stress biomarkers and how they are modulated by the treatment were not investigated. Such experiments are recommended in future investigations.

In conclusion, the present study demonstrated that MTX was genotoxic to normal human cultured cells, as illustrated by the results of the CA and SCE assays. Conversely, metformin exerted an ameliorative effect against MTX-induced chromosomal injury, as it significantly reduced the CA and SCE frequencies. As the present study was conducted using an in vitro lymphocyte cell culture model, the results are not generalizable to other cell types, and thus additional studies are required.

\section{Acknowledgements}

We would like to thank the Deanship of Research at Jordan University of Science and Technology for financial support to conduct the present study.

\section{Funding}

The present study was funded the Deanship of Research at Jordan University of Science and Technology (grant no. $2020 / 252$ to AR).

\section{Availability of data and materials}

The datasets used and/or analyzed during the present study are available from the corresponding author on reasonable request.

\section{Authors' contributions}

AMR, MA and KHA conceived the study. AMR, KHA, OFK and MA designed the study. AMR, KHA and OFK performed the experiments. AMR and OFK analyzed the data. AMR, OFK and MA wrote the manuscript. AMR, KHA, OFK and MA edited the manuscript. OFK and AMR confirm the authenticity of all the raw data. All authors read and approved the final manuscript.

\section{Ethics approval and consent to participate}

The present study was approved by the Institutional Review Board of Jordan University of Science and Technology (approval no. 27/132/2020). Written informed consent was obtained from all study participants.

\section{Patient consent for publication}

Not applicable.

\section{Competing interests}

The authors declare that they have no competing interests.

\section{References}

1. Bedoui Y, Guillot X, Sélambarom J, Guiraud P, Giry C, Jaffar-Bandjee MC, Ralandison S and Gasque P: Methotrexate an old drug with new tricks. Int J Mol Sci 20: 20, 2019.

2. Tian $\mathrm{H}$ and Cronstein $\mathrm{BN}$ : Understanding the mechanisms of action of methotrexate: Implications for the treatment of rheumatoid arthritis. Bull NYU Hosp Jt Dis 65: 168-173, 2007.

3. Nedelcu RI, Balaban M, Turcu G, Brinzea A, Ion DA, Antohe M, Hodorogea A, Calinescu A, Badarau AI, Popp CG, et al: Efficacy of methotrexate as anti-inflammatory and anti-proliferative drug in dermatology: Three case reports. Exp Ther Med 18: 905-910, 2019.

4. Cai B, Liao A, Lee KK, Ban JS, Yang HS, Im YJ and Chun C: Design, synthesis of methotrexate-diosgenin conjugates and biological evaluation of their effect on methotrexate transport-resistant cells. Steroids 116: 45-51, 2016.

5. Vitale L, Serpieri V, Lauriola M, Piovesan A, Antonaros F, Cicchini E, Locatelli C, Cocchi G, Strippoli P and Caracausi M: Human trisomy 21 fibroblasts rescue methotrexate toxic effect after treatment with 5-methyl-tetrahydrofolate and 5-formyl-tetrahydrofolate. J Cell Physiol Jan 22, 2019 (Epub ahead of print). doi: $10.1002 /$ jcp.28140.

6. Campbell JM, Bateman E, Stephenson MD, Bowen JM, Keefe DM and Peters MD: Methotrexate-induced toxicity pharmacogenetics: An umbrella review of systematic reviews and meta-analyses. Cancer Chemother Pharmacol 78: 27-39, 2016.

7. Howard SC, McCormick J, Pui CH, Buddington RK and Harvey RD: Preventing and Managing Toxicities of High-Dose Methotrexate. Oncologist 21: 1471-1482, 2016.

8. Deneux V,Leboucq N, Saumet L, Haouy S, Akbaraly T and Sirvent N: Acute methotrexate-related neurotoxicity and pseudo-stroke syndrome. Arch Pediatr 24: 1244-1248, 2017 (In French).

9. Watanabe K, Arakawa Y, Oguma E, Uehara T, Yanagi M, Oyama C, Ikeda Y, Sasaki K, Isobe K, Mori M, et al: Characteristics of methotrexate-induced stroke-like neurotoxicity. Int J Hematol 108: 630-636, 2018.

10. Rababa'h AM, Hussein SA, Khabour OF and Alzoubi KH: The protective effect of cilostazol in genotoxicity induced by methotrexate in human cultured lymphocytes. Curr Mol Pharmacol 13: 137-143, 2020.

11. Shahin AA, Ismail MM, Saleh AM, Moustafa HA, Aboul-Ella AA and Gabr HM: Protective effect of folinic acid on low-dose methotrexate genotoxicity. Z Rheumatol 60: 63-68, 2001.

12. Shen J, Deininger P, Hunt JD and Zhao H: 8-Hydroxy2'-deoxyguanosine (8-OH-dG) as a potential survival biomarker in patients with nonsmall-cell lung cancer. Cancer 109: 574-580, 2007. 
13. Martin SA, McCarthy A, Barber LJ, Burgess DJ, Parry S, Lord CJ and Ashworth A: Methotrexate induces oxidative DNA damage and is selectively lethal to tumour cells with defects in the DNA mismatch repair gene MSH2. EMBO Mol Med 1: 323-337, 2009.

14. Taylor OA, Hockenberry MJ, McCarthy K, Gundy P, Montgomery D, Ross A, Scheurer ME and Moore IM: Evaluation of biomarkers of oxidative stress and apoptosis in patients with severe methotrexate neurotoxicity: A case series. J Pediatr Oncol Nurs 32: 320-325, 2015

15. Akbulut S, Elbe H, Eris C, Dogan Z, Toprak G, Otan E, Erdemli E and Turkoz Y: Cytoprotective effects of amifostine, ascorbic acid and $\mathrm{N}$-acetylcysteine against methotrexate-induced hepatotoxicity in rats. World J Gastroenterol 20: 10158-10165, 2014.

16. Cetinkaya A, Bulbuloglu E, Kurutas EB and Kantarceken B $\mathrm{N}$-acetylcysteine ameliorates methotrexate-induced oxidative liver damage in rats. Med Sci Monit 12: BR274-BR278, 2006.

17. Abo-Haded HM, Elkablawy MA, Al-Johani Z, Al-Ahmadi O and El-Agamy DS: Hepatoprotective effect of sitagliptin against methotrexate induced liver toxicity. PLoS One 12: e0174295, 2017.

18. Gaschler MM and Stockwell BR: Lipid peroxidation in cell death. Biochem Biophys Res Commun 482: 419-425, 2017.

19. Dumitrescu R, Mehedintu C, Briceag I, Purcărea VL and Hudita D: Metformin-clinical pharmacology in PCOs. J Med Life 8: 187-192, 2015.

20. Chen K, Li Y, Guo Z, Zeng Y, Zhang W and Wang H: Metformin: Current clinical applications in nondiabetic patients with cancer. Aging (Albany NY) 12: 3993-4009, 2020.

21. Meyerhardt JA, Irwin ML, Jones LW, Zhang S, Campbell N, Brown JC, Pollak M, Sorrentino A, Cartmel B, Harrigan M, et al: Randomized phase II trial of exercise, metformin, or both on metabolic biomarkers in colorectal and breast cancer survivors. JNCI Cancer Spectr 4: pkz096, 2019.

22. Rababa'h AM, Matani BR and Ababneh MA: The ameliorative effects of marjoram in dehydroepiandrosterone induced polycystic ovary syndrome in rats. Life Sci 261: 118353, 2020.

23. Zeng J, Zhu L, Liu J, Zhu T, Xie Z, Sun X and Zhang H: Metformin protects against oxidative stress injury induced by ischemia/ reperfusion via regulation of the lncRNA-H19/miR-148a-3p/ Rock2 Axis. Oxid Med Cell Longev 2019: 8768327, 2019.

24. Cheki M, Ghasemi MS, Rezaei Rashnoudi A and Erfani Majd N: Metformin attenuates cisplatin-induced genotoxicity and apoptosis in rat bone marrow cells. Drug Chem Toxicol: May 9, 2019 (Epub ahead of print). doi: 10.1080/01480545.2019.1609024

25. Tripathi SS, Singh S, Garg G, Kumar R, Verma AK, Singh AK, Bissoyi A and Rizvi SI: Metformin ameliorates acetaminophen-induced sub-acute toxicity via antioxidant property. Drug Chem Toxicol: Sep 2, 2019 (Epub ahead of print). doi: 10.1 080/01480545.2019.1658769.

26. World Medical Association: World Medical Association Declaration of Helsinki: Ethical principles for medical research involving human subjects. JAMA 310: 2191-2194, 2013.

27. Alzoubi KH, Bayraktar E, Khabour O and Al-Azzam SI: Vitamin B12 protects against DNA damage induced by hydrochlorothiazide. Saudi Pharm J 26:786-789, 2018.

28. Al-Eitan LN, Alzoubi KH, Al-Smadi LI and Khabour OF: Vitamin $\mathrm{E}$ protects against cisplatin-induced genotoxicity in human lymphocytes. Toxicol In Vitro 62: 104672, 2020.

29. Rababa'h AM, Khabour OF, Alzoubi KH, Al-Momani D and Ababneh M: Assessment of genotoxicity of levosimendan in human cultured lymphocytes. Curr Mol Pharmacol 12: 160-165, 2019.

30. Fowler S, Roush R and Wise J: Concepts of Biology. OpenStax College. Rice University, 2013

31. Othman EM, Oli RG, Arias-Loza PA, Kreissl MC and Stopper sH: Metformin protects kidney cells from insulin-mediated genotoxicity in vitro and in male Zucker diabetic fatty rats. Endocrinology 157: 548-559, 2016

32. Khabour OF, Enaya FM, Alzoubi K and Al-Azzam SI: Evaluation of DNA damage induced by norcantharidin in human cultured lymphocytes. Drug Chem Toxicol 39: 303-306, 2016.

33. El-Sheikh AA, Morsy MA, Abdalla AM, Hamouda AH and Alhaider IA: Mechanisms of thymoquinone hepatorenal protection in methotrexate-induced toxicity in rats. Mediators Inflamm 2015: 859383, 2015.

34. Luo X, Hu R, Zheng Y, Liu S and Zhou Z: Metformin shows anti-inflammatory effects in murine macrophages through Dicer/ microribonucleic acid-34a-5p and microribonucleic acid-125b-5p J Diabetes Investig 11: 101-109, 2020
35. Nna VU, Abu Bakar AB, Md Lazin M and Mohamed M: Antioxidant, anti-inflammatory and synergistic anti-hyperglycemic effects of Malaysian propolis and metformin in streptozotocin-induced diabetic rats. Food Chem Toxicol 120 305-320, 2018

36. Yang X, Ding H, Qin Z, Zhang C, Qi S, Zhang H, Yang T, He Z, Yang K, Du E, et al: Metformin prevents renal stone formation through an antioxidant mechanism in vitro and in vivo. Oxid Med Cell Longev 2016: 4156075, 2016.

37. Kolivand S, Motevaseli E, Cheki M, Mahmoudzadeh A, Shirazi A and Fait V: The anti-apoptotic mechanism of metformin against apoptosis induced by ionizing radiation in human peripheral blood Mononuclear Cells. Klin Onkol 30: 372-379, 2017.

38. Stults DM, Killen MW, Marco-Casanova P and Pierce AJ: The Sister Chromatid Exchange (SCE) assay. Methods Mol Biol 2102: 441-457, 2020.

39. Mosesso P and Cinelli S: In vitro cytogenetic assays: Chromosomal aberrations and micronucleus tests. Methods Mol Biol 2031: 79-104, 2019

40. Mahmoodi M, Soleyman-Jahi S, Zendehdel K, Mozdarani H, Azimi C, Farzanfar F, Safari Z, Mohagheghi MA, Khaleghian M, Divsalar K, et al: Chromosomal aberrations, sister chromatid exchanges, and micronuclei in lymphocytes of oncology department personnel handling anti-neoplastic drugs. Drug Chem Toxicol 40: 235-240, 2017

41. Norppa H, Bonassi S, Hansteen IL, Hagmar L, Strömberg U, Rössner P, Boffetta P, Lindholm C, Gundy S, Lazutka J, et al: Chromosomal aberrations and SCEs as biomarkers of cancer risk. Mutat Res 600: 37-45, 2006.

42. Mondello C, Giorgi R and Nuzzo F: Chromosomal effects of methotrexate on cultured human lymphocytes. Mutat Mutat Res Lett 139: 67-70, 1984.

43. Atteritano M, Mazzaferro S, Mantuano S, Bagnato GL and Bagnato GF: Effects of infliximab on sister chromatid exchanges and chromosomal aberration in patients with rheumatoid arthritis. Cytotechnology 68: 313-318, 2016

44. Said Salem NI, Noshy MM and Said AA: Modulatory effect of curcumin against genotoxicity and oxidative stress induced by cisplatin and methotrexate in male mice. Food Chem Toxicol 105 370-376, 2017.

45. Chukwunonso Obi B, Chinwuba Okoye T, Okpashi VE, Nonye Igwe $\mathrm{C}$ and Olisah Alumanah E: Comparative study of the antioxidant effects of metformin, glibenclamide, and repaglinide in alloxan-induced diabetic rats. J Diabetes Res 2016: 1635361 , 2016.

46. Tang G, Yang H, Chen J, Shi M, Ge L, Ge X and Zhu G: Metformin ameliorates sepsis-induced brain injury by inhibiting apoptosis, oxidative stress and neuroinflammation via the PI3K/Akt signaling pathway. Oncotarget 8: 97977-97989, 2017.

47. Cahova M, Palenickova E, Dankova H, Sticova E, Burian M Drahota Z, Cervinkova Z, Kucera O, Gladkova C, Stopka P, et al: Metformin prevents ischemia reperfusion-induced oxidative stress in the fatty liver by attenuation of reactive oxygen species formation. Am J Physiol Gastrointest Liver Physiol 309: G100-G111, 2015.

48. Ashoka $\mathrm{CH}$ and Mustak M: Antigenotoxic effects of rutin against methotrexate genotoxicity in Swiss albino mice. Curr Trends Biotechnol Pharm 13: 163-177, 2019.

49. Mai X, Zhou F, Lin P, Lin S, Gao J, Ma Y, Fan R, Ting W, Huang C, Yin D, et al: Metformin scavenges formaldehyde and attenuates formaldehyde-induced bovine serum albumin crosslinking and cellular DNA damage. Environ Toxicol 35: 1170-1178, 2020.

50. Kanigür-Sultuybek G, Ozdas SB, Curgunlu A, Tezcan V and Onaran I: Does metformin prevent short-term oxidant-induced dna damage? In vitro study on lymphocytes from aged subjects. J Basic Clin Physiol Pharmacol 18: 129-140, 2007.

51. Lee YS, Doonan BB, Wu JM and Hsieh TC: Combined metformin and resveratrol confers protection against UVC-induced DNA damage in A549 lung cancer cells via modulation of cell cycle checkpoints and DNA repair. Oncol Rep 35: 3735-3741, 2016.

52. Sritawan N, Prajit R, Chaisawang P, Sirichoat A, Pannangrong W, Wigmore $\mathrm{P}$ and Welbat JU: Metformin alleviates memory and hippocampal neurogenesis decline induced by methotrexate chemotherapy in a rat model. Biomed Pharmacother 131: 110651, 2020.

53. Wessels JA, Huizinga TW and Guchelaar HJ: Recent insights in the pharmacological actions of methotrexate in the treatment of rheumatoid arthritis. Rheumatology (Oxford) 47: 249-255, 2008

54. Alqarni AM and Zeidler MP: How does methotrexate work? Biochem Soc Trans 48: 559-567, 2020. 